\title{
Defect State Assisted Z-scheme Charge Recombinationin Bi2O2CO3/Graphene Quantum DotComposites For Photocatalytic Oxidation of NO
}

Liu, Yang; Zhou, Ying; Yu, Shan; Xie, Zhanghui; Chen, Yi; Zheng, Kaiwen; Mossin, Susanne; Lin, Weihua; Meng, Jie; Pullerits, Tonu

Total number of authors:

11

Published in:

ACS Applied Nano Materials

Link to article, DOI:

10.1021/acsanm.9b02276

Publication date:

2020

Document Version

Publisher's PDF, also known as Version of record

Link back to DTU Orbit

Citation $(A P A)$ :

Liu, Y., Zhou, Y., Yu, S., Xie, Z., Chen, Y., Zheng, K., Mossin, S., Lin, W., Meng, J., Pullerits, T., \& Zheng, K. (2020). Defect State Assisted Z-scheme Charge Recombinationin $\mathrm{Bi}_{2} \mathrm{O}_{2} \mathrm{CO}_{3} /$ Graphene Quantum DotComposites For Photocatalytic Oxidation of NO. ACS Applied Nano Materials , 3(1), 772-781. https://doi.org/10.1021/acsanm.9b02276

\section{General rights}

Copyright and moral rights for the publications made accessible in the public portal are retained by the authors and/or other copyright owners and it is a condition of accessing publications that users recognise and abide by the legal requirements associated with these rights.

- Users may download and print one copy of any publication from the public portal for the purpose of private study or research.

- You may not further distribute the material or use it for any profit-making activity or commercial gain

- You may freely distribute the URL identifying the publication in the public portal 


\section{Defect State Assisted Z-scheme Charge Recombination in $\mathrm{Bi}_{2} \mathrm{O}_{2} \mathrm{CO}_{3} /$ Graphene Quantum Dot Composites For Photocatalytic Oxidation of NO}

Yang Liu, Ying Zhou,* Shan Yu, Zhanghui Xie, Yi Chen, Kaiwen Zheng, Susanne Mossin, Weihua Lin, Jie Meng, Tonu Pullerits, and Kaibo Zheng*

Cite This: ACS Appl. Nano Mater. 2020, 3, 772-781

Read Online

ACCESS | Lill Metrics \& More | 回 Article Recommendations

Supporting Information

ABSTRACT: In this work, we explored the photoinduced charge carriers dynamics rationalizing the photocatalytic oxidation of $\mathrm{NO}$ over $\mathrm{N}$-doped $\mathrm{Bi}_{2} \mathrm{O}_{2} \mathrm{CO}_{3}$ /graphene quantum dots composites(N-BOC/GQDs) via timeresolved photoluminescence (TRPL). Under visible light illumination, only GQDs can be photoexcited and inject electrons to N-BOC within $0.5 \mathrm{~ns}$. Under UV light irradiation, the interfacial Z-scheme heterojunction recombination between the electrons in N-BOC and holes in GQDs dominate the depopulation of excited states within $0.36 \mathrm{~ns}$. Such efficient Z-scheme recombination regardless of the large energy difference $(1.66 \mathrm{eV})$ is mediated by the interfacial oxygen vacany defect states characterized by both density functional theory calculations (DFT) and electron paramagnetic resonance (EPR) measurement. This finding provide a novel strategic view to improve the photocatalytic performance of the nanocomposite by interfacial engineer-

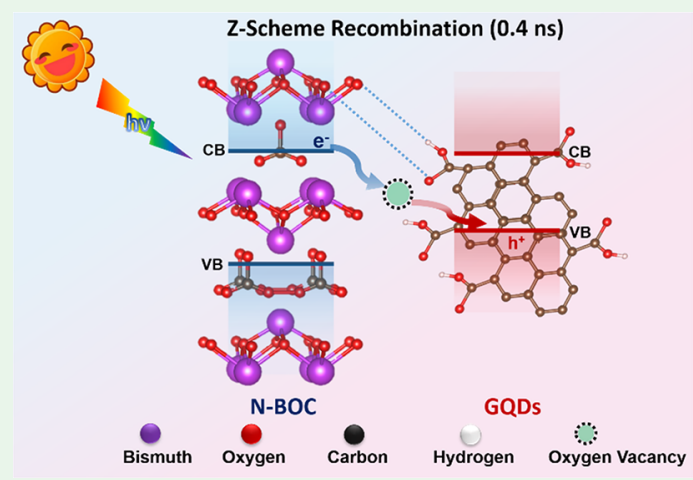
ing

KEYWORDS: time-resolved spectroscopy, interfacial Z-scheme heterojunction, interfacial oxygen vacancy, NO oxdiation

\section{INTRODUCTION}

Since it was pioneered by Fujishima in 1972, photocatalysis has been considered as a promising technique for environmental remediation. ${ }^{1,2}$ Various photocatalysts such as plasmonic metals, metal oxides and metal-free compounds have been explored in the last 40 years. $^{3-10}$ Among these photocatalysts, bismuth subcarbonate $\left(\mathrm{Bi}_{2} \mathrm{O}_{2} \mathrm{CO}_{3}, \mathrm{BOC}\right)$ with typical sillen phase and unique alternating $\left[\mathrm{Bi}_{2} \mathrm{O}_{2}{ }^{2+}\right]$ as well orthogonal intercalated $\mathrm{CO}_{3}{ }^{2-}$ layers has attracted highly attention due to their low-toxicity and specific anisotropic structure resulting in internal static electric field. ${ }^{1-14}$ Such internal static electric fields in $\mathrm{Bi}_{2} \mathrm{O}_{2} \mathrm{CO}_{3}$ layered structure are expected to promote the directed charge carrier transportation. ${ }^{15,16}$ However, their poor absorption coefficient as well as the large optical band gap $(3.3 \mathrm{eV})$ restricts the capability of light harvesting during photocatalytic reaction.

Such bottlenecks can be resolved by integrating BOC with additional light harvesters including plasmonic metals, metal oxides, and metal-free compounds to form composites. ${ }^{17-21}$ Graphene quantum dots (GQDs) have long been recognized as superior visible light absorbers owing to their high chemical stability, tunable optical band gap, and accessible surface chemistry. ${ }^{22-28}$ In our previous work, we decorated nitrogen doped $\mathrm{Bi}_{2} \mathrm{O}_{2} \mathrm{CO}_{3}$ (N-BOC) with $-\mathrm{COOH}$ or hydroxyl $-\mathrm{OH}$ functioned GQDs to construct nanocomposites, which exhibited approximately 5 times higher photocatalytic activity over NO removal compared to pristine BOC. ${ }^{29}$ The enhanced photocatalytic performance was expected but not yet rationalized thoroughly. How the extra charge carrier generated by light excitation in GQDs contributes to the photocatalytic reaction in the nanocomposites needs to be illustrated. Most importantly, both GQDs and N-BOC possess numerous sub-bandgap trap states induced by surface dangling bonds or other volume defects, ${ }^{16,30,31}$ but they seem to be unharmful for the photocatalytic process. Investigation on the photoinduced charge carrier dynamics is therefore highly essential to manifest the underlying mechanism.

In the present work, both steady state and time-resolved photoluminescence spectroscopies have been utilized to monitor the photoinduced charge carriers' separation and recombination dynamics of the N-BOC/GQDs with different GQDs ratios. We found that electrons generated from GQDs transfer to the conduction band (CB) of N-BOC within $0.5 \mathrm{~ns}$ under visible light illumination. Under UV illumination where

Received: November 20, 2019

Accepted: January 2, 2020

Published: January 2, 2020 

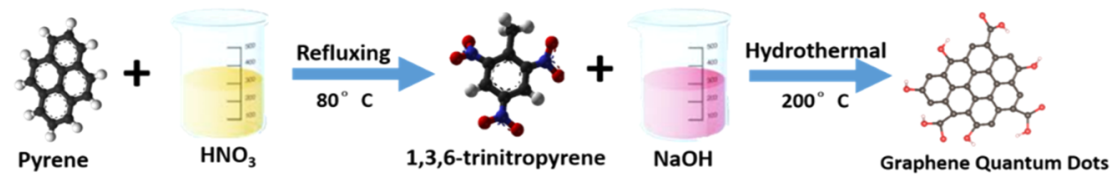

$\mathbf{a}$
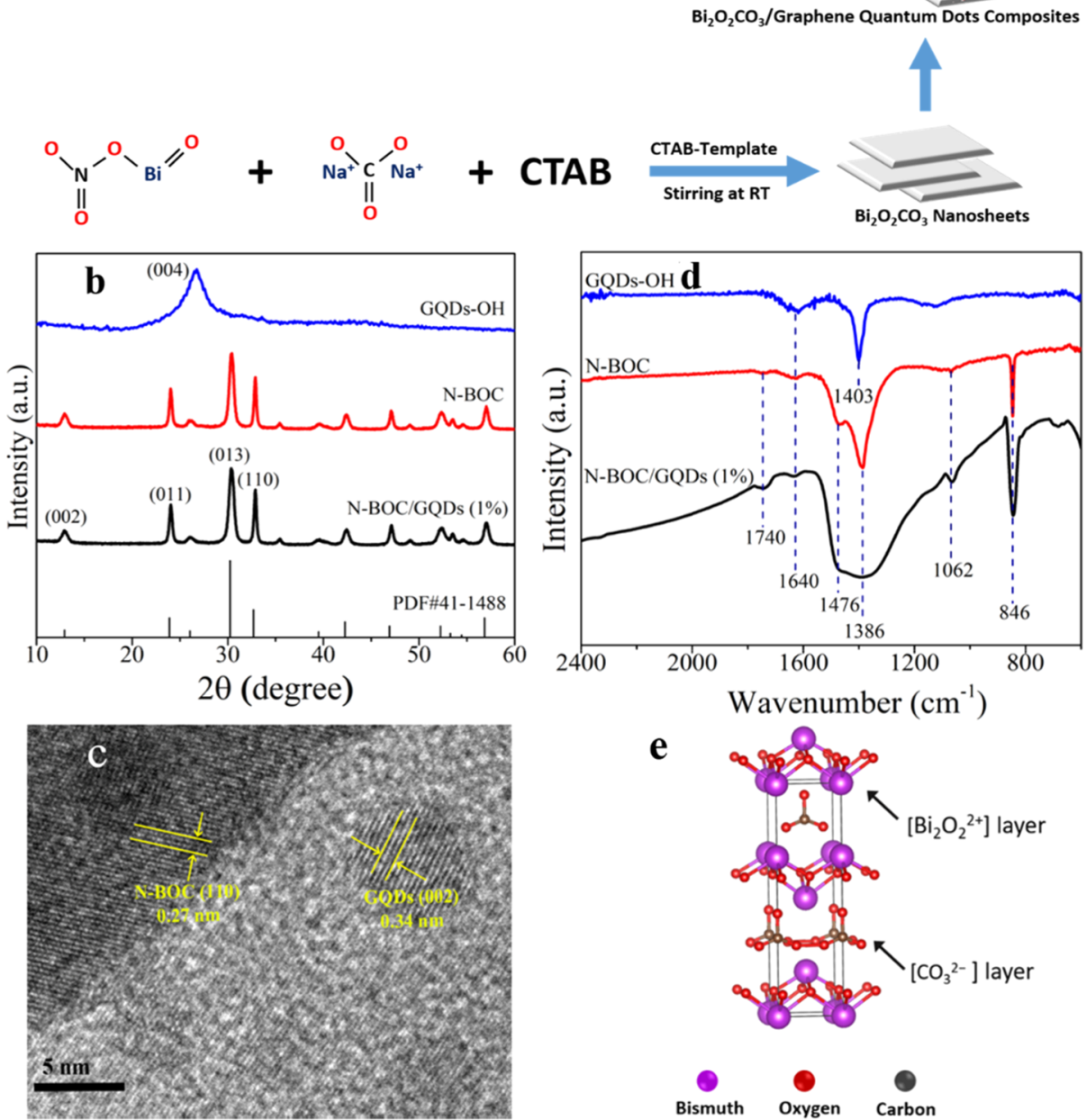

Figure 1. (a) Schematic illustration of the formation process of the N-BOC/GQDs composites. (b) XRD patterns of GQDs, N-BOC, and N-BOC/ GQDs and the corresponding PDF card information; (c) HRTEM of N-BOC/GQDs (1\%) composite; (d) FT-IR spectra of GQDs, N-BOC, and N-BOC/GQDs composites; (e) Crystal structure of $\mathrm{Bi}_{2} \mathrm{O}_{2} \mathrm{CO}_{3}$.

both GQDs and N-BOC are excited, the electrons generated from N-BOC will recombine with holes on the valence band (VB) of GQDs via Z-scheme heterojunction within $0.4 \mathrm{~ns}$, and the residual electrons/holes in both parts will be trapped by trap states. We further confirmed by the electron paramagnetic resonance (EPR) measurements that the integration of GQDs introduce additional $\mathrm{O}^{-}$radical defects, which facilitates the $\mathrm{Z}$ scheme recombination via multiphoton emission. We believe it is the main photophysical origin of the enhanced photocatalytic performance in N-BOC/GQDs nanocomposites.

\section{EXPERIMENTAL SECTION}

2.1. Materials. All the chemical reagents were analytical grade purchased from Chengdu Kelong Co. Ltd. with used without any further purification.

2.2. Synthesis of $\mathrm{N}-\mathrm{BOC}$ Nanosheets. Nitrogen doped $\mathrm{Bi}_{2} \mathrm{O}_{2} \mathrm{CO}_{3}$ (N-BOC) nanosheets with size of $200 \mathrm{~nm}$ were synthesized base on our previous method. ${ }^{16}$ First of all, $4.85 \mathrm{~g}$ of
$\mathrm{Bi}\left(\mathrm{NO}_{3}\right)_{3} \cdot 5 \mathrm{H}_{2} \mathrm{O}$ was dissolved in $10 \mathrm{~mL}$ of $\mathrm{HNO}_{3}(1 \mathrm{M})$ which was labeled as solution A. Next, $8.45 \mathrm{~g}$ sodium carbonate $\left(\mathrm{Na}_{2} \mathrm{CO}_{3}\right)$ as well as $1 \mathrm{~g}$ cetyltrimethylammonium bromide (CTAB) were dissolved into $90 \mathrm{~mL}$ of water as solution B. Then, we add solution B into solution A drop-wisely within $30 \mathrm{~min}$ and stirring at $30{ }^{\circ} \mathrm{C}$ for $1 \mathrm{~h}$. Afterward, the resultant precipitate was filtered and washed three times with isopropanol and ultrapure water. Finally, final solid products were collected and dried under vacuum at $60{ }^{\circ} \mathrm{C}$.

2.3. Synthesis of GQDs. The alkali-mediated hydrothermal method has been implemented to synthesis graphene quantum dots (GQDs). ${ }^{32,33}$ First, $2 \mathrm{~g}$ of pyrene (purity $>98 \%$ ) was treated in 160 $\mathrm{mL}$ hot $\mathrm{HNO}_{3}$ under refluxing condition at $80{ }^{\circ} \mathrm{C}$ and stirring for 12 $\mathrm{h}$ to obtain yellow 1,3,6-trinitropyrene. Then, $0.75 \mathrm{~g}$ of 1,3,6trinitropyrene was dispersed in $150 \mathrm{~mL}$ sodium hydroxide $(\mathrm{NaOH})$ solution with aq $0.2 \mathrm{M}$ and ultrasonicated for $2 \mathrm{~h}$ to get a homogeneous suspension. Second, we transferred this suspension into a $250 \mathrm{~mL}$ Teflon-lined stainless-steel autoclave and heated at $200{ }^{\circ} \mathrm{C}$ for $10 \mathrm{~h}$. Insoluble impurities were removed via filtration $(0.22 \mu \mathrm{m}$ filter) when temperature cooling down. Third, remaining solution was 


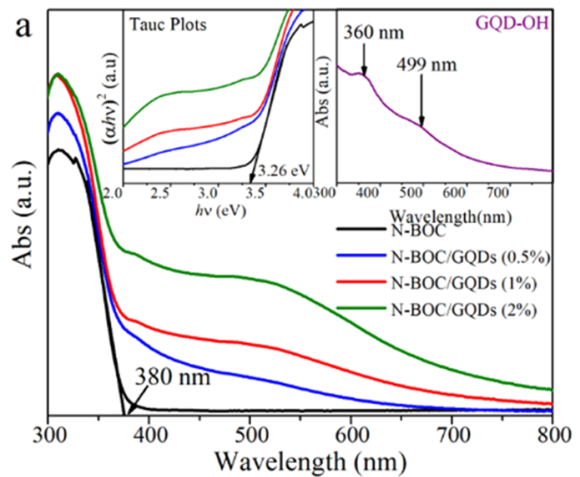

b
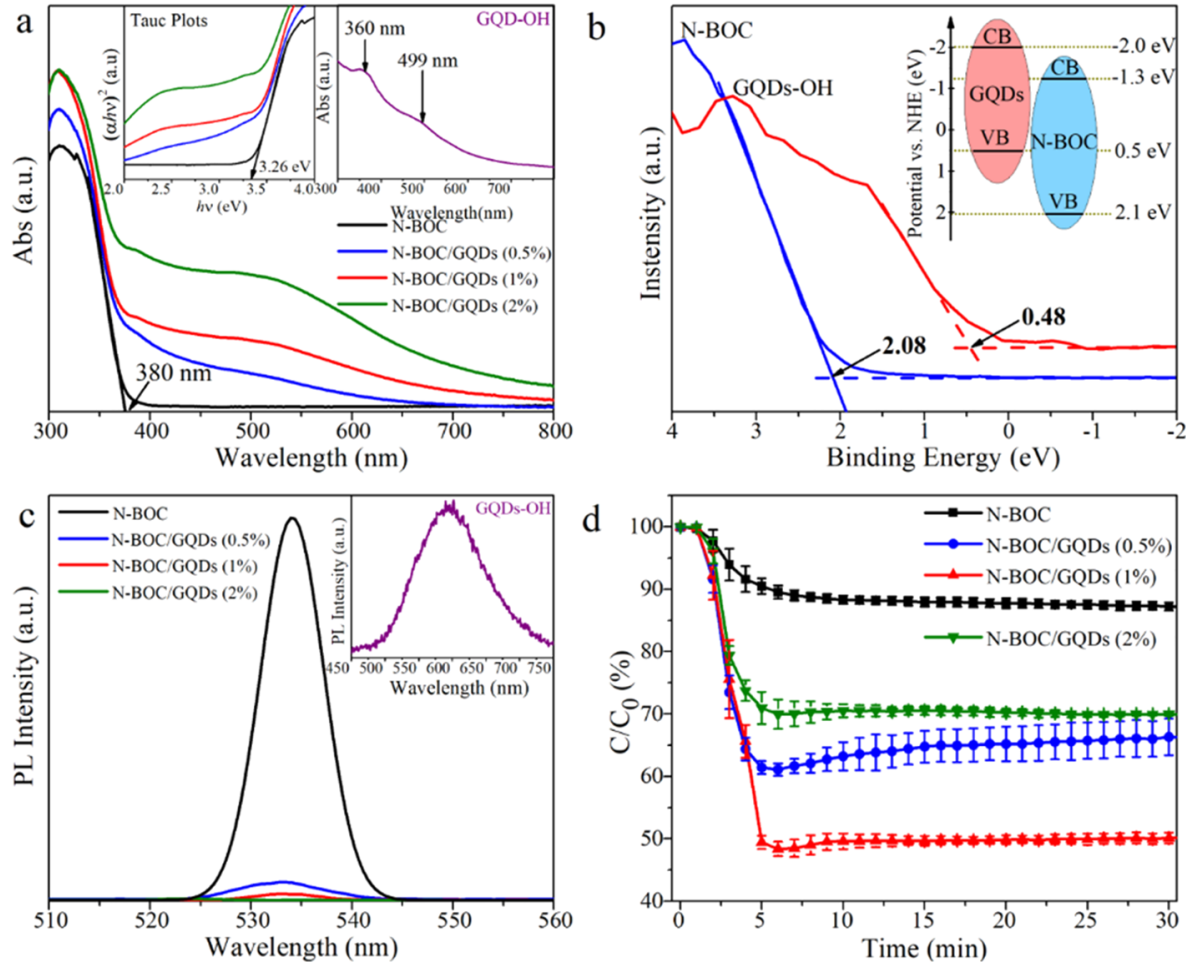

Figure 2. (a) UV-DRS of N-BOC/GQDs composites. Inset is the absorption spectrum of GQDs dispersed in water; (b) XPS valence band spectra of N-BOC and GQDs with energy band structure; (c) PL spectra of GQDs, N-BOC and N-BOC/GQDs composites. (Excitation wavelength: 420 $\mathrm{nm}, 280 \mathrm{~nm}$ for GQDs and N-BOC composites, respectively); (d) Photocatalytic oxidation of NO over BOC and N-BOC/GQDs under visible light irradiation $(\lambda>420 \mathrm{~nm})$.

then further purified with dialysis bags for $48 \mathrm{~h}$ so that the residual sodium salt as well as undissolved small molecules (with retained molecular weight: $3500 \mathrm{Da}$ ) can be removed. At last, GQDs solution with deep-brown color can be obtained, which could be further collected as solid crystals by rotary evaporation.

2.4. Synthesis of N-BOC/GQDs Composites Photocatalysts. All the N-BOC/GQDs composites used in this system were synthesized base on our previous reported method. ${ }^{29,34}$ Typically, $200 \mathrm{mg}$ of the N-BOC powder as well as $2 \mathrm{mg}$ GQDs were dispersed into $100 \mathrm{~mL}$ DI water. Then, all the samples were ultrasonicated for $30 \mathrm{~min}$ and stirring for $5 \mathrm{~h}$ to obtain homogeneous suspension. After that, the suspension was centrifugated and precipitated was evaporated under $60{ }^{\circ} \mathrm{C}$ to get the dried solid composites. At last, all the relevant composites were obtained and named as N-BOC/ GQDs (0.5\%), N-BOC/GQDs (1\%), and N-BOC/GQDs (2\%), respectively, which corresponds to 1,2 , and $4 \mathrm{mg}$ of GQDs in mass ratio.

2.5. Structural Characterization. Powder X-ray diffraction (PXRD) was performed with a PANalytical X'pert diffractometer operated at $40 \mathrm{kV}$ and $40 \mathrm{~mA}$ using $\mathrm{Cu} \mathrm{K} \alpha$ radiation. The highresolution transmission electron microscopy (HRTEM) images were recorded on FEI Tecnai G2 20 microscope operated at $200 \mathrm{kV}$.

2.6. Steady-State Spectroscopies. UV-vis diffuse reflection spectra (UV-DRS) was performed on an Agilent 8453 UV-vis spectrometer pectrophotometer. Fourier transform infrared spectra (FT-IR) was performed on a Nicolet 6700 spectrometer. X-ray photoelectron spectroscopy (XPS) was performed on a Thermo Scientific XPS spectrometer, with $\mathrm{Al} \mathrm{K \alpha}$ radiation $(1486 \mathrm{eV})$ as the excitation X-ray source. Photoluminescence (PL) was performed via Spex Fluorolog 1681 standard spectrofluorometer.

2.7. Time-Resolved Photoluminescence Spectroscopies. Time-resolved photoluminescence (TRPL) measurement was performed using a Time-correlated single photon counting setup (TCSPC) utilizing a pulsed diode laser which is triggered externally at $5 \mathrm{MHz}$ to excite the sample at 438 and $375 \mathrm{~nm}$, the pulse duration of the laser is about $40 \mathrm{ps}$. The emitted photons were detected by a fast avalanche photodiode (SPAD, Micro Photon Device) with response time less than $50 \mathrm{ps}$ after passing through a $450 \mathrm{~nm}$ long band-pass filter. $^{35,36}$

2.8. Photocatalytic Measurements. Our homemade NO photodegraded testing system has been utilized to measure the photocatalytic performance, which has been described in our previous work. $^{29}$ In our experiment, dry air $\left(2.0 \mathrm{~L} \mathrm{~min}^{-1}\right)$ mixed with NO

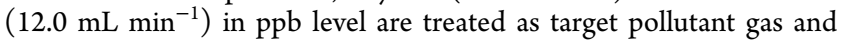
the removal ratio $(\eta)$ of $\mathrm{NO}$ was calculated by the equation $\eta(\%)=$ $\left(1-C / C_{0}\right) \times 100 \%$, where $\mathrm{C}$ is the concentration of NO during the photoreaction and $C_{0}$ represents the initial concentration of $\mathrm{NO}$ before photocatalytic reaction.

2.9. EPR Measurement. Electron paramagnetic resonance (EPR) spectra were recorded at room temperature and $77 \mathrm{~K}$ on powdered samples (approximately $20 \mathrm{mg}$ ) on a cw Bruker EMX X-band spectrometer fitted with a ST4102 cavity and a liquid nitrogen finger dewar.

2.10. Calculation Methods. All calculations were investigated via density functional theory (DFT) together with the projectedaugmented plane wave method as implemented in Vienna ab initio simulation package (VASP). Generalized gradient approximation (GGA) with Perdew-Burke-Ernzer-hof (PBE) functional of the electrons was selected to evaluate the exchange-correlation. The Monkhorst-Pack mesh of $2 \times 2 \times 1$ k-points here are selected to sample the Brillouin zone in order to optimize the geometry as well as electronic structure calculations. In this system, the plane-wave cutoff energy and energy convergence tolerance is $400 \mathrm{eV}$ and $10^{-4} \mathrm{eV}$, respectively. Moreover, all atomic positions are relaxed at the PBE level until the atomic forces are less than $0.05 \mathrm{eV} / \AA$.

\section{RESULTS AND DISCUSSION}

3.1. Structure and Steady-State Spectroscopies. The GQDs, $\mathrm{Bi}_{2} \mathrm{O}_{2} \mathrm{CO}_{3}$, and N-BOC/GQDs composites was synthesized via refluxing and magnetic stirring method and the possible formation mechanism was illustrated in Figure 1a. 

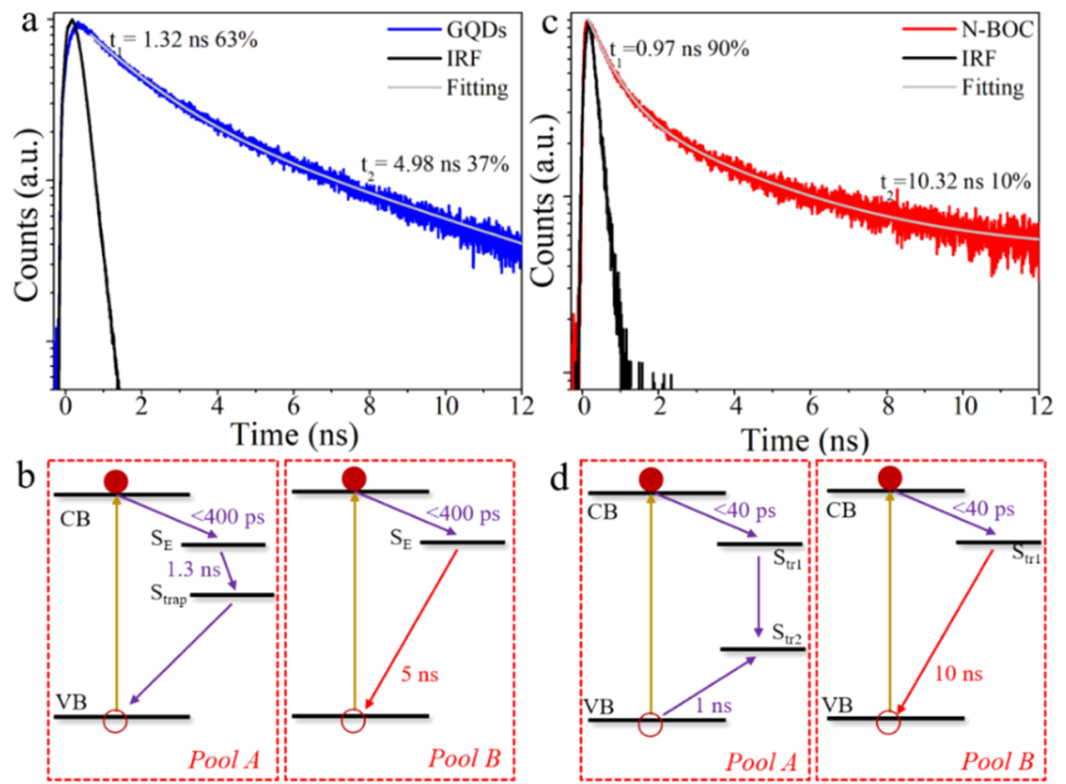

Figure 3. (a,b) TCSPC kinetics of GQDs and N-BOC, $(b, d)$ schematics of the recombination pathways for GQDs and N-BOC, respectively.

Moreover, according to our previous work, sample N-BOC/ GQDs (1\%) exhibited best photocatalytic performance toward NO photo-oxidation among all composites and therefore be selected for the following test. Figure $1 \mathrm{~b}$ displays the XRD of GQDs, N-BOC, and N-BOC/GQDs composites. The broad peak located at around $2 \theta=26.61^{\circ}$ is characteristic of the bulk graphite with a (002) layer spacing equal to $3.34 \AA$, which indicates successful synthesis of GQDs with high graphitization. ${ }^{37}$ Compared to pristine N-BOC, N-BOC/GQDs (1\%) exhibit same diffraction peak in XRD patterns positions which could be well indexed to tetragonal $\mathrm{Bi}_{2} \mathrm{O}_{2} \mathrm{CO}_{3}$ (JCPDS card no. 41-1488). The characteristic peaks located at $12.9^{\circ}, 23.9^{\circ}$, $30.3^{\circ}, 32.7^{\circ}, 42.3^{\circ}, 47.0^{\circ}, 53.4^{\circ}$, and $56.9^{\circ}$ could be attributed to the crystal facets of (002), (011), (013), (110), (114), (020), (121), and (123), respectively. This demonstrated that the crystal structure of N-BOC was not destroyed after coupling with GQDs. On the other hand, the characteristic diffraction peak of GQDs cannot be clearly observed in $\mathrm{N}$ BOC/GQDs composites, which may result from the low content along with the random distribution of GQDs on the surface of N-BOC. ${ }^{29}$

Supporting Information (SI) Figure S1 demonstrates the SEM images of N-BOC/GQDs composites with a size of hundreds of $2 \mathrm{D}$ nanosheets. Moreover, high-resolution TEM (HRTEM) has been carried out to verify the samples crystal structure which is showed in Figure 1c. ${ }^{29}$ GQDs around 3-5 $\mathrm{nm}$ can be clearly resolved with an atomic spacing of $0.34 \mathrm{~nm}$ corresponding to the (002) plane and size distribution of QDs from also provided in SI Figure S2. After that, the interaction between GQDs and N-BOC was investigated by FT-IR measurement plotted in Figure 1d. The small broad peak situated at 1640 and $1402 \mathrm{~cm}^{-1}$ correspond to skeletal vibrations of graphene domains and stretching vibration of $\mathrm{O}-$ $\mathrm{H}$ for GQDs only while the peaks located at 846, 1062, and $1740 \mathrm{~cm}^{-1}$ can be attributed to the out-of-plane bending mode of $\mathrm{CO}_{3}{ }^{2-}$ group and the antisymmetric vibration mode of $\mathrm{CO}_{3}{ }^{2-}$ group, respectively. ${ }^{23,38-40}$ Compared with N-BOC/ GQDs physical mixture (SI Figure S3), the broadening as well as red-shift of the peak at $1386 \mathrm{~cm}^{-1}$ with red-shift from 1403 to $1386 \mathrm{~cm}^{-1}$ in N-BOC/GQDs compared to pristine GQDs $\left(1403 \mathrm{~cm}^{-1}\right)$ is a fingerprint of hydrogen bond formation between the two components via magnetic stirring in water. ${ }^{41}$

Figure $2 \mathrm{a}$ shows the ground state absorption spectra of GQDs and N-BOC composites measured by UV-vis diffuse reflection spectroscopy. The pristine GQDs exhibited a broad absorption band from 300 to $800 \mathrm{~nm}$, from the both absorption of the QDs as well as the surface states. ${ }^{36,42-44}$ The two characteristic absorption peaks located at 360 and 490 $\mathrm{nm}$ are related to the $n \rightarrow \pi^{*}$ electron transition in the molecular orbital of carbonyl groups $(\mathrm{C}=\mathrm{O})$ in GQDs. ${ }^{44-47}$ The absorption spectra of all N-BOC/GQDs composites are composed of the absorption band edge of neat N-BOC (380 $\mathrm{nm}, 3.26 \mathrm{eV}$ ) and the broad absorption band at $490 \mathrm{~nm}$ from GQDs. The absorbance of $490 \mathrm{~nm}$ band increases gradually with an incremental amount of GQDs. ${ }^{29}$ According to the XPS valence band spectra in Figure $2 b$, the valence band maximum positions for N-BOC and GQDs are 2.08 and $0.48 \mathrm{eV}$, respectively, whereas the conduction band minimum position can be calculated as $-1.18 \mathrm{eV}$ and $-2.0 \mathrm{eV}$ taking into account the optical band gaps extracted from the Tauc plots of the absorption spectra inset of Figure $2 \mathrm{a}$. It should be noted the difference between optical band gap and electronic band gap of $\mathrm{N}-\mathrm{BOC}$ and GQDs can be neglected due to the relatively low exciton binding energy. ${ }^{48}$ The energy band structures were summarized in Figure $2 \mathrm{~b}$. Figure $2 \mathrm{c}$ shows the steady state photoluminescence spectra of the samples. The emission band of GQDs at $600 \mathrm{~nm}$ given in the inset of Figure $2 \mathrm{c}$ is assigned to the radiative recombination of the charge carrier at the surface states induced by the oxygen functional groups. ${ }^{33} \mathrm{On}$ the other hand, the emission peak of neat N-BOC $(535 \mathrm{~nm})$ is drastically red-shifted compared with the absorption band edge $(380 \mathrm{~nm})$. Such sub-band gap radiative recombination is usually attributed to the defect emission in particular related to the $\mathrm{O}$ vacancy that would trap excited electrons from the conduction band. ${ }^{49,50}$ After adding GQDs in the composites, the PL of N-BOC has been overwhelmingly quenched as depicted in Figure $2 c$ indicating extra emissive state depopulation pathway (e.g., charge transfer) has been introduced as well the enhanced charge separation efficiency. ${ }^{51,52}$ Figure $2 \mathrm{~d}$ demonstrates the performance of 


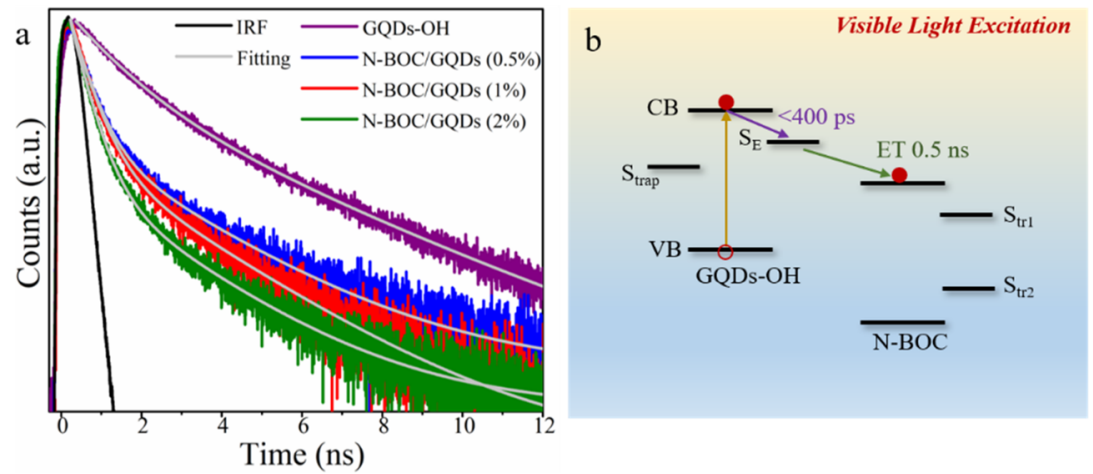

Figure 4. (a) TCSPC kinetics of N-BOC/GQDs composites with $600 \mathrm{~nm}$ long pass filter, Excitation wavelength: $438 \mathrm{~nm}$. (b) Schematic illustration of charge carriers transfer dynamics

photocatalytic NO oxidation of both neat N-BOC and composites. All the samples were pre-exposed to the NO atmosphere for $30 \mathrm{~min}$ to reach the surface adsorptiondesorption equilibrium before photocatalytic reaction. The $\mathrm{N}$ BOC/GQDs composites (N-BOC/GQDs 1\%) exhibited superior photocatalytic performance with the maximal $\mathrm{NO}$ removal ratio 5 times higher than that of the pristine N-BOC. In order to understand the mechanism of improvement of the photocatalytic performance, the changes of the surface area of these samples studied first in SI Figure S4. BET surface area of $\mathrm{N}-\mathrm{BOC}, \mathrm{N}-\mathrm{BOC} / \mathrm{GQDs}(0.5 \%)$, N-BOC/GQDs (1\%), and $\mathrm{N}$-BOC/GQDs (2\%) is 24.81, 22.10, 20.91, and $25.62 \mathrm{~m}^{2} / \mathrm{g}$, which means the enhanced photocatalytic activity can be attributed to increased light harvest as well as charge separation efficiency instead of the influence of surface area. $^{29}$ On the other hand, N-BOC/GQDs (1\%) exhibited the best photocatalytic activity in all the investigated samples and therefore has been selected for the photocatalytic recycling test, which is provided in SI Figures S5 and S6. ${ }^{29}$ Compared with the photocatalytic oxidation in liquid phase, ${ }^{53,54} \mathrm{NO}$ photo-oxidation take place in solid-gas phase, and the degradation product $\mathrm{NO}_{3}^{-}$cannot dissolve in any solvent, but can be adsorbed on the surface of the sample to block the active sites which finally causes the decrease of photocatalytic performance.

In order to fully elucidate the photocatalytic mechanism, we investigate the detailed excited state dynamics by the timeresolved photoluminescence. It started with the study on the neat N-BOC and GQDs samples. Figure $3 a$ and $b$ illustrates PL decay dynamics of both pristine GQDs (excited at $438 \mathrm{~nm}$ ) and N-BOC (excited at $375 \mathrm{~nm}$ ). The PL kinetics of GQDs exhibit a rising edge slower than the instrument response function (IRF, $<50 \mathrm{ps}$ ) with a lifetime of $400 \mathrm{ps}\left(\tau_{1}\right)$, which can be attributed to the depopulation of the initial excited states to the surface emissive states. On the contrary, the rising of kinetics for N-BOC is instantaneous indicating the trapping process (i.e., from band edge states to oxygen vacancy defect emissive states) should be faster than the instrument response (40 ps). The PL decays can be perfectly fitted using biexponential decay equation. ${ }^{55,56}$

$$
f(t)=A_{1} \mathrm{e}^{-t / \tau_{1}}+A_{2} \mathrm{e}^{-t / \tau_{2}}
$$

where $\tau$ is the lifetime of the different components, and $A$ is the contribution ratio of each component to the total decay. The PL decay of neat GQDs consists of one major fast component $(1.32 \pm 0.01 \mathrm{~ns}, 63 \%)$ and one minor slow component $(4.98 \pm 0.02 \mathrm{~ns}, 37 \%)$. First it should be noted that the excitation fluence is kept low enough $\left(5 \times 10^{11} \mathrm{ph} / \mathrm{cm}^{2}\right)$ to exclude any high order Auger recombination. In general, the $\operatorname{PLQY}(\eta)$ could be evaluated as the fraction of radiative recombination among all the recombination processes of the charge carrier as

$$
\eta=\frac{\sum_{i} A_{i} k_{\mathrm{rad}}^{i}}{\sum_{i} A_{i} k_{\mathrm{rad}}^{i}+\sum_{j} A_{j} k_{\mathrm{nonrad}}^{j}}
$$

where $k_{\text {rad }}$ and $K_{\text {nonrad }}$ are the rates of the radiative and nonradiative recombination processes, respectively, and $A_{\mathrm{i}, \mathrm{j}}$ represents the amplitude of each decay component. If we assume the $1.32 \pm 0.01 \mathrm{~ns}$ and $4.98 \pm 0.02 \mathrm{~ns}$ components are related to nonradiative and radiative recombination processes, respectively. The calculated PLQY (13.4\%) is in good correspondence with the result from a direct steady state PL measurement. ${ }^{57}$ Therefore, we can assign the fast component to extra trapping processes (pool $\mathrm{A}$ in Figure $3 \mathrm{~b}$ ), while the slow component with the lifetime of $5 \pm 0.02 \mathrm{~ns}\left(\tau_{2}\right)$ corresponds to intrinsic radiative recombination within the other pool of GQDs free of trap states (pool B in Figure 3b). ${ }^{41}$ Apart from the oxygen based functional groups, there are also remaining carboxylic groups on the surface of GQDs (FT-IR spectra in Figure 1b), which could probably serve as electron acceptors related to the fast trapping process stated above. In neat N-BOC, the PL decays can be fitted by a dominating fast component $(1 \pm 0.01 \mathrm{~ns}, 90 \%)$ and a minor slow component $(10 \pm 0.08 \mathrm{~ns}, 10 \%)$ as shown in Figure $3 \mathrm{c}$. As the absolute PLQY of N-BOC is undetectable $(\ll 1 \%)$, we can conclude that the major decay component is attributed to the charge carrier trapping resulting in quenching of the PL emission (pool A in Figure 3d), while there still remains minor partition of the N-BOC without any trap states that would undergo slow radiative recombination (pool $\mathrm{B}$ in Figure $3 \mathrm{~d}$ ). Contrary to GQDs, the trapping in N-BOC is more likely to be attributed to the hole trapping from the unoccupied $\mathrm{N} 2 \mathrm{p}$ states near the $\mathrm{VB}$ as shown in Figure $3 \mathrm{~b} .^{16}$

The excited states dynamics in N-BOC/GQDs composites was then investigated afterward. Here, two excitation wavelengths of 438 and $375 \mathrm{~nm}$ were employed where the former can only excite the GQDs, whereas the latter ensure the excitation of both components in the composites. We also utilize $600 \mathrm{~nm}$ long-pass or $530 \mathrm{~nm}$ band-pass filter, to selectively monitor the emission from each component using their steady-state emission spectra as reference. Figure 4 exhibits the PL kinetics of GQDs in the composites with various GQDs content using $438 \mathrm{~nm}$ excitation. The decays 
Table 1. TRPL Lifetimes and the Respective Amplitude of GQDs, N-BOC, and N-BOC/GQDs Composites (0.5\%, 1\% and 2\%); Excitation Wavelength: $438 \mathrm{~nm}$

\begin{tabular}{|c|c|c|c|c|c|c|}
\hline \multicolumn{2}{|c|}{ probe wavelength } & $\mathrm{N}-\mathrm{BOC}$ & GQDs & $0.5 \%$ & $1 \%$ & $2 \%$ \\
\hline $600 \mathrm{~nm}$ & $t_{1}(\mathrm{~ns})$ & & $1.32 \pm 0.01$ & $0.57 \pm 0.01$ & $0.51 \pm 0.01$ & $0.48 \pm 0.01$ \\
\hline & $t_{2}(\mathrm{~ns})$ & & $4.98 \pm 0.01$ & $5.4 \pm 0.02$ & $4.15 \pm 0.02$ & $4.23 \pm 0.02$ \\
\hline & $A_{1}(\%)$ & & $63 \%$ & $93 \%$ & $92 \%$ & $97 \%$ \\
\hline
\end{tabular}
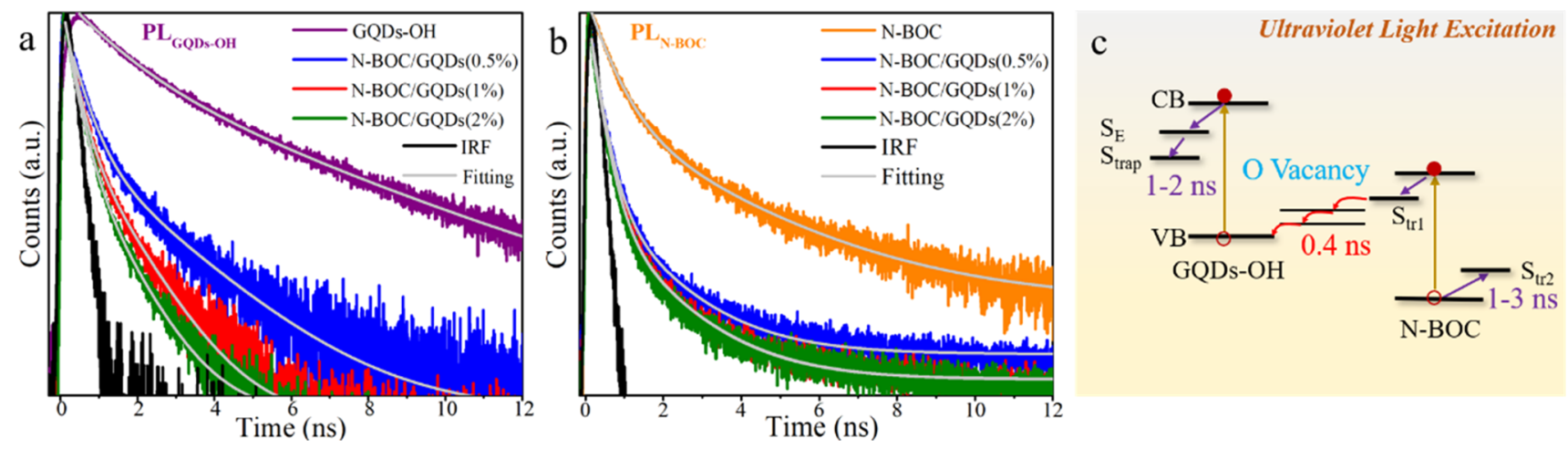

Figure 5. TCSPC kinetics of N-BOC/GQDs composite with (a) $600 \mathrm{~nm}$ long pass filter and (b) $530 \mathrm{~nm}$ band-pass filter; (c) Schematic illustration of charge carriers transfer dynamics. Excitation wavelength: $375 \mathrm{~nm}$.

Table 2. TRPL Lifetimes and the Respective Amplitude of GQDs, N-BOC, and N-BOC/GQDs Composites (0.5\%, 1\%, and 2\%); Excitation Wavelength: $375 \mathrm{~nm}$

\begin{tabular}{|c|c|c|c|c|c|c|}
\hline \multicolumn{2}{|c|}{ probe wavelength } & N-BOC & GQDs & $0.5 \%$ & $1 \%$ & $2 \%$ \\
\hline \multirow[t]{3}{*}{$600 \mathrm{~nm}$} & $t_{1}(\mathrm{~ns})$ & & $1.06 \pm 0.01$ & $0.40 \pm 0.01$ & $0.36 \pm 0.01$ & $0.32 \pm 0.01$ \\
\hline & $t_{2}(\mathrm{~ns})$ & & $4.97 \pm 0.01$ & $1.98 \pm 0.02$ & $1.92 \pm 0.02$ & $1.47 \pm 0.02$ \\
\hline & $A_{1}(\%)$ & & $69 \%$ & $95 \%$ & $98 \%$ & $95 \%$ \\
\hline \multirow[t]{3}{*}{$530 \mathrm{~nm}$} & $t_{1}(\mathrm{~ns})$ & $0.97 \pm 0.01$ & & $0.31 \pm 0.01$ & $0.36 \pm 0.01$ & $0.36 \pm 0.01$ \\
\hline & $t_{2}(\mathrm{~ns})$ & $10.3 \pm 0.08$ & & $2.35 \pm 0.01$ & $2.47 \pm 0.01$ & $2.6 \pm 0.02$ \\
\hline & $A_{1}(\%)$ & $90 \%$ & & $98 \%$ & $99 \%$ & $99 \%$ \\
\hline
\end{tabular}

can be well fitted by two exponential components with lifetime of a dominating fast component around $0.5 \mathrm{~ns}(>90 \%)$ and minor long components around $5 \mathrm{~ns}$, respectively (Table 1 ). The slow component resembles the intrinsic radiative recombination as indicated by the neat GQDs' results in Table 1, which should be related to some minor unattached GQDs free from the interaction to N-BOC. The lifetime of the major fast component $(0.5 \mathrm{~ns})$ is faster than the intrinsic trapping of GQDs, and therefore should be assigned to the electron injection to the conduction band of N-BOCs since it is energetically favorable as shown in Figure $4 \mathrm{~b}$. Moreover, the photoinduced charge carrier dynamics we stressed here are all ultrafast, within a nanosecond time scale, whereas all the photocatalytic chemical reactions (i.e., NO reduction, scavenges of holes, etc.) should be at least initiated within $\mu$ s to ms or even longer. This means after photoexcitation in the equilibrium condition, the only available photogenerated species for the photocatalytic reaction in our system is the hole at the valence band (VB) of GQDs and electrons at the conduction band (CB) of N-BOC. Therefore, we can conclude that the photocatalytic reaction in this scenario emerges via the hole at the VB of GQDs and electrons at the CB of N-BOC. ${ }^{29}$ We also noticed PL decays of GQDs' emission in Figure 4a become faster with increasing GQDs content indicating enhanced charge transfer process with more GQDs addition. We believe such an efficient charge separation process plays a critical role for the photocatalytic performance of the composites. $^{17-21,58,59}$ However, as the emission of N-BOC cannot be tracked under visible light excitation, the recombination pathway for injection electrons in $\mathrm{N}-\mathrm{BOC}$ is by far not clear.

When UV excitation is employed where both N-BOC and GQDs can be excited, the excited state dynamics looks entirely different. Figure 5 demonstrates the PL decay kinetics of $\mathrm{N}$ BOC/GQDs composite with excitation wavelength of $375 \mathrm{~nm}$. As shown in Figure 5a and b, all PL kinetic curves of N-BOC/ GQDs composites decay faster compared to pristine GQDs as well as N-BOC, which indicates excited charge carriers in both $\mathrm{N}-\mathrm{BOC}$ and GQDs would undergo additional depopulation processes in the composites. According to fitting results (Table 2 ), both PL decays from the emission of GQDs and N-BOC, consisting of the dominate fast component with almost the same lifetimes around $0.36 \mathrm{~ns}$. One possible explanation for the fast decay components in both GQDs and N-BOC is the electron injection from $\mathrm{CB}$ of GQDs to N-BOC together with the hole injection from VB of N-BOC to GQDs. However, such situation can be excluded as 1 . the decay time $(0.36 \mathrm{~ns})$ is significantly faster than the electron injection time observed under visible excitation $(0.5 \mathrm{~ns})$; and 2 . the rates for electron and hole injection are not likely to be identical considering different driving forces and electronic coupling for charge transfer between $\mathrm{CB}$ and VB. Alternatively, we suggest that the synchronized emissive state depopulation between N-BOC and GQDs can be attributed to the $\mathrm{Z}$-scheme recombination as 


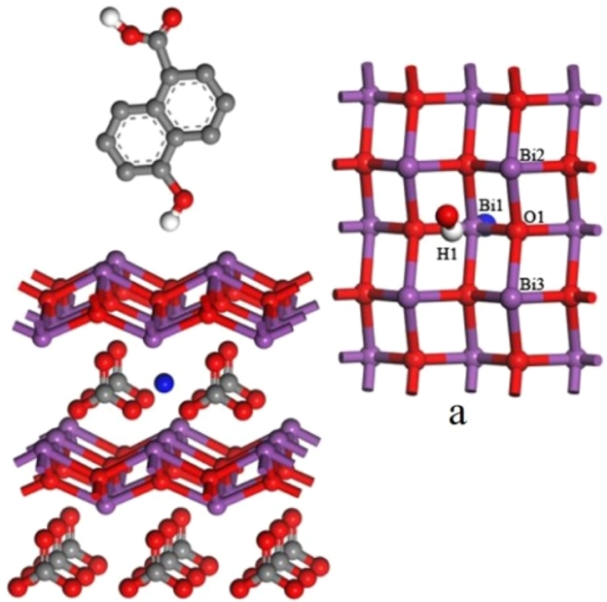

(1)

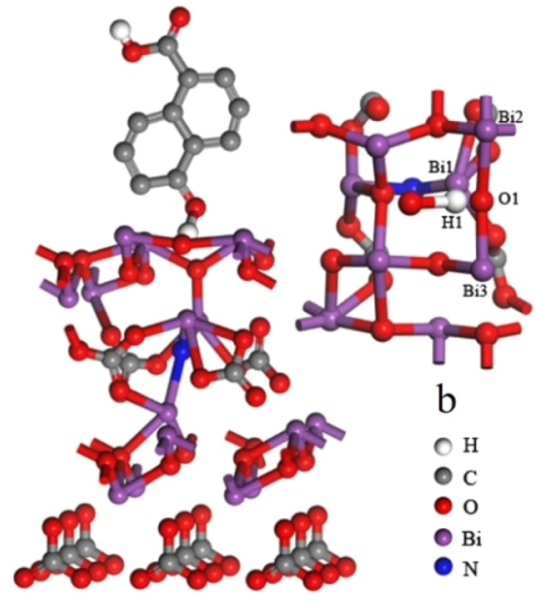

(2)

Figure 6. (1) Computational model of the N-BOC/GQDs composites interface and (2) optimized interface structure ((a) and (b) demonstrates the top view the N-BOC/GQDs composites computational interface of geometries before and after optimization).

shown in Figure 5c. The residual excited electrons in the $\mathrm{CB}$ of GQDs and holes in the VB of N-BOC can be further trapped to the defect states which can be not directly identified via TRPL results. The efficient $\mathrm{Z}$-scheme recombination resolved in our system is surprising due to the large energetic shift between VBM of GQDs and CBM of N-BOC $(1.66 \mathrm{eV})$.

3.3. The Interfacial Interaction. In order to employ the interfacial interaction as well such Z-scheme recombination, periodic calculations have been carried out by using the firstprinciple theory. Figure 6 demonstrates the computational model and optimized geometries of N-BOC/GQDs composites' interface, and Table 3 list the $\mathrm{Bi}-\mathrm{O}$ and hydrogen bonds

Table 3. Length of Hydrogen Bonds and $\mathrm{Bi}-\mathrm{O}$ Bonds in $\mathrm{N}$ BOC/GQDs Composites

\begin{tabular}{lcccc} 
& $\begin{array}{c}\mathrm{O} 1-\mathrm{H} 1 \\
(\AA)\end{array}$ & $\begin{array}{c}\mathrm{O} 1-\mathrm{Bi} 1 \\
(\AA)\end{array}$ & $\begin{array}{c}\mathrm{O} 1-\mathrm{Bi} 2 \\
(\AA)\end{array}$ & $\begin{array}{c}\mathrm{O} 1-\mathrm{Bi} 3 \\
(\AA)\end{array}$ \\
$\begin{array}{l}\text { before optimized } \\
\text { after optimized }\end{array}$ & 2.77 & 2.90 & 2.11 & 2.17 \\
\hline
\end{tabular}

at interface, respectively. Before optimization, the $\mathrm{H}_{1}$ atom on hydroxyl groups exhibiting a distance of $2.77 \AA$ with $\mathrm{O} 1$ atom. But after optimization, the $\mathrm{H} 1$ atom moves closer to $\mathrm{O} 1$ atom $(0.92 \AA)$ and 0.63 electrons transfer from GQDs to N-BOC according to the analysis of Mulliken charge partition scheme, indicating the formation of the intermolecular hydrogen bond in composites' surface as well the strong interfacial interaction between BOC and GQDs, which is consistent with XPS analysis in SI Figure S7. ${ }^{29,60,61}$ Moreover, it is clear that the BOC surface has obvious distortions after bridging with GQDs via hydrogen bonds as illustrated in Figure 6. In this circumstance, $\mathrm{Bi}-\mathrm{O}$ bonds such as $\mathrm{Bi} 1-\mathrm{O} 1, \mathrm{Bi} 2-\mathrm{O} 1$, and Bi3-O1 are extend from 2.9, 2.11, 2.17 to 3.15, 2.42, and 2.24 $\AA$ respectively, which are all in meta-broken status. As a result, the $\mathrm{O}$ atoms have been extracted from $\left[\mathrm{Bi}_{2} \mathrm{O}_{2}\right]^{2+}$ layer and led to formation of oxygen vacancy in BOC surface. To confirm the oxygen vacancy, EPR measurements were carried out and are illustrated in Figure 7. A clear EPR signal can be observed in N-BOC/GQDs at $g=2.0039$, which is usually assigned to the superoxide radical at the surface oxygen vacancy sites of $\mathrm{N}$ BOC, whereas no signal can be resolved in neat N-BOC samples. $^{62,63}$ The intensity of the signal (double integral of the spectra shown in Figure 7a) increases with the amount of the GQDs in Figure $7 \mathrm{~b}$. The surface oxygen vacancy should be formed by the displacement of the surface $\mathrm{O}$ atoms due to their strong hydrogen bonding toward GQDs, which is also observed in a similar N-BOC/organic molecule system. ${ }^{15}$ Such defect states reside below the $\mathrm{CB}$ of the N-BOC as shown in Figure $5 \mathrm{c}$ providing efficient pathways for Z-type recombination through multiphonon emission. ${ }^{64,65}$ The results perfectly interpret the drastically enhanced NO photocatalytic perform-
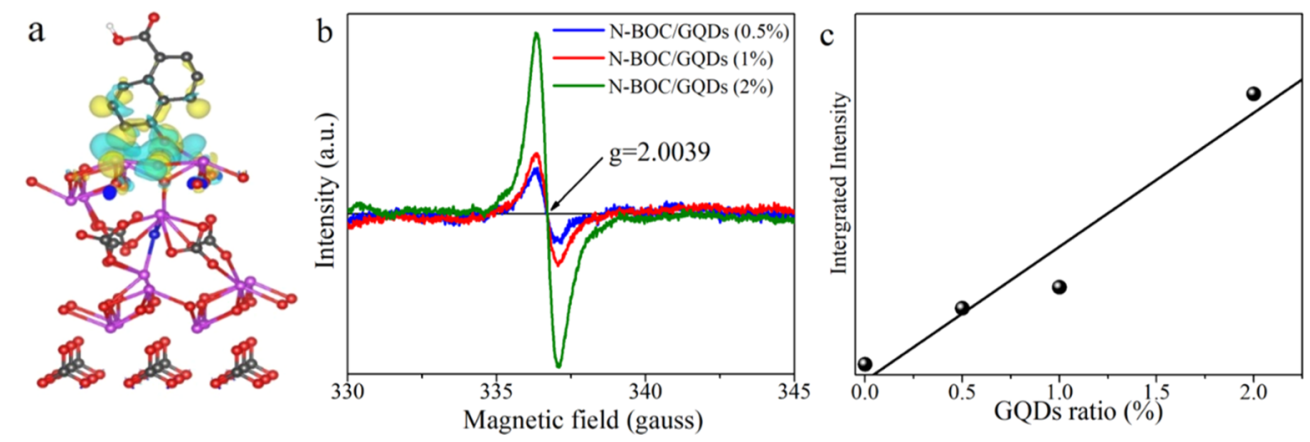

Figure 7. (a) Charge density difference and the amount of charge transfer $(\Delta q$, e) of N-BOC/GQDs. (Yellow areas mean electron depletion and blue areas indicate electron accumulation with an isosurface value of 0.003 electrons per $\AA^{3}$.) (b) EPR spectrum of N-BOC/GQDs composites, (c) integrated EPR intensity vs GQDs ratio in the composites. 
ance of the composites compared with pristine N-BOC in our previous studies. ${ }^{29}$ The pathway of $\mathrm{Z}$-scheme recombination at $\mathrm{N}-\mathrm{BOC} / \mathrm{GQDs}$ interface is demonstrated in Figure 8.

\section{Z Scheme Recombination (0.4 ns)}

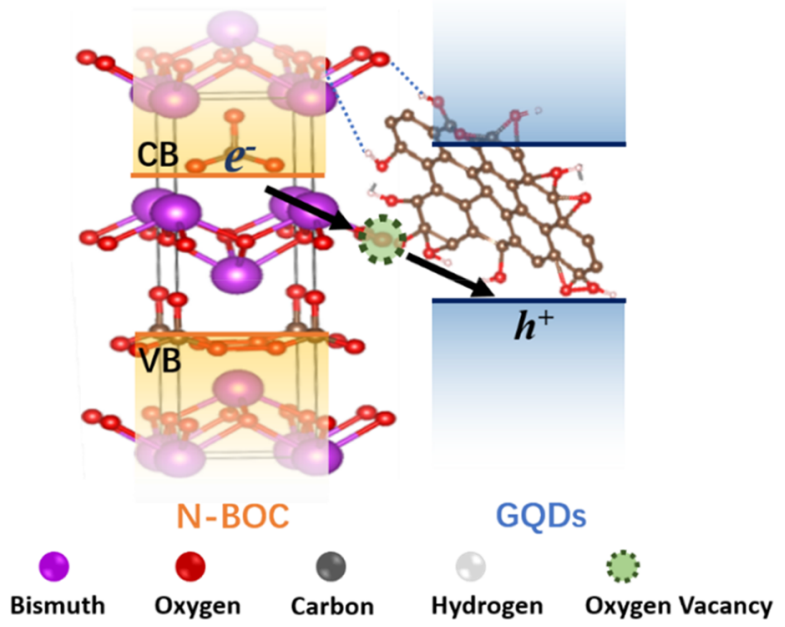

Figure 8. Schematic representation of atomic structures of N-BOC/ GQDs composite. The atoms with yellow circles and blue short dash line stand for the oxygen vacancy sites and hydrogen bond, respectively.

\section{CONCLUSIONS}

In conclusion, we successfully reveal the photoinduced charge carrier dynamics of N-BOC/GQDs nanocomposite with enhanced photocatalytic performance toward NO photooxidation using time-resolved photoluminescence spectroscopy. We first discover the charge carrier recombination dynamics in neat N-BOC and GQDs, which are strongly determined by the defect trapping. For visible light illumination of the composite sample, where only GQDs can be excited, the photogenerated electrons in GQDs would be injected to N-BOC within $0.5 \mathrm{~ns}$ leaving the holes in the valence band of GQDs. When the composite is excited by UV light, the interfacial charge transfer is replaced by efficient Zscheme recombination between the holes at the valence band of the GQDs and electrons at the defect states of N-BOC within $0.36 \mathrm{~ns}$. This indicates that the $\mathrm{Z}$-scheme photocatalytic system can be formed via the interfacial oxygen vacancy defect states due to the strong interaction between N-BOC and GQDs, which was confirmed by DFT calculation and EPR measurement. Notably, oxygen vacancy assisted Z-scheme recombination has also been suggested for other heterojunction systems. ${ }^{66-68}$ Our results experimentally confirm the pathway and time scale of such recombination, which provide reference for materials design and engineering for the photocatalytic composites.

\section{ASSOCIATED CONTENT}

\section{(s) Supporting Information}

The Supporting Information is available free of charge at https://pubs.acs.org/doi/10.1021/acsanm.9b02276.

Figures S1-S7 (PDF)

\section{AUTHOR INFORMATION}

\section{Corresponding Authors}

Ying Zhou - Southwest Petroleum University, Chengdu, China; (1) orcid.org/0000-0001-9995-0652;

Email: yzhou@swpu.edu.cn

Kaibo Zheng - Lund University, Lund, Sweden, and Technical University of Denmark, Kongens Lyngby, Denmark; 이이.org/0000-0002-7236-1070; Email: kaibo.zheng@chemphys.lu.se

\section{Other Authors}

Yang Liu - Southwest Petroleum University, Chengdu, China, and Lund University, Lund, Sweden

Shan Yu - Southwest Petroleum University, Chengdu, China

Zhanghui Xie - Southwest Petroleum University, Chengdu, China

Yi Chen - Southwest Petroleum University, Chengdu, China

Kaiwen Zheng - Southwest Petroleum University, Chengdu, China

Susanne Mossin - Technical University of Denmark, Kongens Lyngby, Denmark; (1) orcid.org/0000-00017763-9660

Weihua Lin - Lund University, Lund, Sweden

Jie Meng - Technical University of Denmark, Kongens Lyngby, Denmark; (1) orcid.org/0000-0002-3813-5221

Tonu Pullerits - Lund University, Lund, Sweden; (1) orcid.org/0000-0003-1428-5564

Complete contact information is available at:

https://pubs.acs.org/10.1021/acsanm.9b02276

\section{Notes}

The authors declare no competing financial interest.

\section{ACKNOWLEDGMENTS}

We gratefully acknowledge financial support from the National Natural Science Foundation of China (U1862111), the Sichuan Provincial International Cooperation Project (2017HH0030), the Innovative Research Team of Sichuan Province (2016TD0011), Independent Research Fund Denmark-Nature Sciences (DFF-FNU, Project No DFF-701400302), Independent Research Fund Denmark-Sapere Aude starting grant (No. 7026-00037A), and Swedish Research Council VR starting grant (No. 2017-05337). Y.L., J.M., and W.L. also acknowledge financial support from China Scholarship Council (Nos. 201808510198, 201806320345, and 201806460021).

\section{REFERENCES}

(1) Fujishima, A.; Honda, K. Photolysis-decomposition of water at the surface of an irradiated semiconductor. Nature 1972, 238, 37-38.

(2) Fujishima, A.; Zhang, X.; Tryk, D. Heterogeneous photocatalysis: From water photolysis to applications in environmental clean-up. Int. J. Hydrogen Energy 2007, 32, 2664-2672.

(3) Zhang, X.; Yu, S.; Liu, Y.; Zhang, Q.; Zhou, Y. Photoreduction of non-noble metal $\mathrm{Bi}$ on the surface of $\mathrm{Bi}_{2} \mathrm{WO}_{6}$ for enhanced visible light photocatalysis. Appl. Surf. Sci. 2017, 396, 652-658.

(4) Hattori, Y.; Abdellah, M.; Rocha, I.; Pavliuk, M. V.; Fernandes, D. L. A.; Sá, J. Light-induced ultrafast proton-coupled electron 
transfer responsible for $\mathrm{H}_{2}$ evolution on silver plasmonic. Mater. Today 2018, 21, 590-593.

(5) Pavliuk, M. V.; Fernandes, A. B.; Abdellah, M.; Fernandes, D. L. A.; Machado, C. O.; Rocha, I.; Hattori, Y.; Paun, C.; Bastos, E. L.; Sá, J. Nano-hybrid plasmonic photocatalyst for hydrogen production at 20\% efficiency. Sci. Rep. 2017, 7, 8670-8679.

(6) Cui, Z.; Dong, X.; Sun, Y.; Zhou, Y.; Zhang, Y.; Dong, F. Simultaneous introduction of oxygen vacancies and $\mathrm{Bi}$ metal onto the $\{001\}$ facet of $\mathrm{Bi}_{3} \mathrm{O}_{4} \mathrm{Cl}$ woven nanobelts for synergistically enhanced photocatalysis. Nanoscale 2018, 10, 16928-16934.

(7) Zhao, Z.; Cao, Y.; Dong, F.; Wu, F.; Li, B.; Zhang, Q.; Zhou, Y. The activation of oxygen through oxygen vacancies in $\mathrm{BiOCl} / \mathrm{PPy}$ to inhibit toxic intermediates and enhance the activity of photocatalytic nitric oxide removal. Nanoscale 2019, 11, 6360-6367.

(8) Pavliuk, M. V.; Abdellah, M.; Sá, J. Hydrogen evolution with $\mathrm{Cs} \mathrm{PbBr}_{3}$ perovskite nanocrystals under visible light in solution, Mater. Today. Commun. 2018, 16, 90-96.

(9) Tang, J.; Durrant, J.; Klug, D. Mechanism of Photocatalytic Water Splitting in $\mathrm{TiO}_{2}$ Reaction of Water with Photo-holes, Importance of Charge Carrier Dynamics, and Evidence for FourHole Chemistry. J. Am. Chem. Soc. 2018, 130, 13885-13891.

(10) Xiong, T.; Wang, H.; Zhou, Y.; Sun, Y.; Cen, W.; Huang, H.; Zhang, Y.; Dong, F. KCl-mediated dual electronic channels in layered g- $\mathrm{C}_{3} \mathrm{~N}_{4}$ for enhanced visible light photocatalytic NO removal. Nanoscale 2018, 10, 8066-8074.

(11) He, R.; Cao, S.; Zhou, P.; Yu, J. Recent advances in visible light Bi-based photocatalysts. Chin. J. Catal. 2014, 35, 989-1007.

(12) Chen, P.; Sun, Y.; Liu, H.; Zhou, Y.; Jiang, G.; Lee, S.; Zhang, Y.; Dong, F. Facet-dependent photocatalytic NO conversion pathways predetermined by adsorption activation patterns. Nanoscale 2019, 11, 2366-2373.

(13) Liang, N.; Zai, J.; Xu, M.; Zhu, Q.; Wei, X.; Qian, X. Novel $\mathrm{Bi}_{2} \mathrm{~S}_{3} / \mathrm{Bi}_{2} \mathrm{O}_{2} \mathrm{CO}_{3}$ heterojunction photocatalysts with enhanced visible light responsive activity and wastewater treatment. J. Mater. Chem. A 2014, 2, 4208-4216.

(14) Dong, F.; Sun, Y.; Fu, M.; Ho, W.; Lee, S.; Wu, Z. Novel in situ $\mathrm{N}$-Doped $(\mathrm{BiO})_{2} \mathrm{CO}_{3}$ hierarchical microspheres self-assembled by nanosheets as efficient and durable visible light driven photocatalyst. Langmuir 2012, 28, 766-773.

(15) Zhao, Z.; Zhou, Y.; Wang, F.; Zhang, K.; Yu, S.; Cao, K. Polyaniline-decorated $\{001\}$ facets of $\mathrm{Bi}_{2} \mathrm{O}_{2} \mathrm{CO}_{3}$ nanosheets: in situ oxygen vacancy formation and enhanced visible light photocatalytic activity. ACS Appl. Mater. Interfaces 2015, 7, 730-737.

(16) Zhou, Y.; Zhao, Z.; Wang, F.; Cao, K.; Doronkin, D.; Dong, F.; Grunwaldt, J. Facile synthesis of surface $\mathrm{N}$-doped $\mathrm{Bi}_{2} \mathrm{O}_{2} \mathrm{CO}_{3}$ : Origin of visible light photocatalytic activity and in situ DRIFTS studies. J. Hazard. Mater. 2016, 303, 163-172.

(17) Hu, J.; Zhang, D.; Deng, N.; Xu, Q.; Li, H.; He, J.; Lu, J. In situ fabrication of $\mathrm{Bi}_{2} \mathrm{O}_{2} \mathrm{CO}_{3} / \mathrm{MoS}_{2}$ on carbon nanofibers for efficient photocatalytic removal of NO under visible-light irradiation. Appl. Catal., B 2017, 217, 224-231.

(18) Dong, F.; Li, Q.; Sun, Y.; Ho, W. Noble Metal-like behaviour of plasmonic $\mathrm{Bi}$ particles as a cocatalyst deposited on $(\mathrm{BiO})_{2} \mathrm{CO}_{3}$ microspheres for efficient visible light photocatalysis. ACS Catal. 2014, 4, 4341-4350.

(19) Zhang, Y.; Wang, L.; Dong, F.; Chen, Q.; Jiang, H.; Xu, M.; Shi, J. Non-additional carbon source one-step synthesis of $\mathrm{Bi}_{2} \mathrm{O}_{2} \mathrm{CO}_{3}$ based ternary composite for efficient Z Z-scheme photocatalysis. J. Colloid Interface Sci. 2019, 536, 575-585.

(20) Huang, Y.; Zhu, D.; Zhang, Q.; Zhang, Y.; Cao, J.; Shen, Z.; $\mathrm{Ho}, \mathrm{W}$.; Lee, S. Synthesis of a $\mathrm{Bi}_{2} \mathrm{O}_{2} \mathrm{CO}_{3} / \mathrm{ZnFe}_{2} \mathrm{O}_{4}$ heterojunction with enhanced photocatalytic activity for visible light irradiationinduced NO removal. Appl. Catal., B 2018, 234, 70-78.

(21) Zhao, H.; Lia, G.; Tian, F.; Jia, Q.; Liu, Y.; Chen, R. g- $\mathrm{C}_{3} \mathrm{~N}_{4}$ surface-decorated $\mathrm{Bi}_{2} \mathrm{O}_{2} \mathrm{CO}_{3}$ for improved photocatalytic performance: Theoretical calculation and photodegradation of antibiotics in actual water matrix. Chem. Eng. J. 2019, 366, 468-479.
(22) Li, X.; Rui, M.; Song, J.; Shen, Z.; Zeng, H. Carbon and graphene quantum dots for optoelectronic and energy devices: A Review. Adv. Funct. Mater. 2015, 25, 4929-4947.

(23) Zhou, S.; Shao, M.; Lee, S. Up-conversion and downconversion fluorescent graphene quantum dots: ultrasonic preparation and photocatalysis. ACS Nano 2012, 6, 1059-1064.

(24) Pan, D.; Jiao, J.; Li, Z.; Guo, Y.; Feng, C.; Liu, Y.; Wang, L.; $\mathrm{Wu}, \mathrm{M}$. Efficient separation of electron-hole pairs in graphene quantum dots by $\mathrm{TiO}_{2}$ heterojunctions for dye degradation. ACS Sustainable Chem. Eng. 2015, 3, 2405-2413.

(25) Yu, H.; Zhao, Y.; Zhou, C.; Shang, L.; Peng, Y.; Cao, Y.; Wu, L.; Tung, C.; Zhang, T. Carbon quantum dots $/ \mathrm{TiO}_{2}$ composites for efficient photocatalytic hydrogen evolution. J. Mater. Chem. A 2014, 2, 3344-3351.

(26) Wang, S.; Cole, I.; Li, Q. Quantum-confined bandgap narrowing of $\mathrm{TiO}_{2}$ nanoparticles by graphene quantum dots for visible-light-driven applications. Chem. Commun. 2016, 52, 92089211.

(27) Hao, Y.; Dong, X.; Wang, X.; Zhai, S.; Ma, H.; Zhang, X. Controllable electrostatic self-assembly of sub-3 nm graphene quantum dots incorporated into mesoporous $\mathrm{Bi}_{2} \mathrm{MoO}_{6}$ frameworks: efficient physical and chemical simultaneous co-catalysis for photocatalytic oxidation. J. Mater. Chem. A 2016, 4, 8298-8307.

(28) Zou, J.; Wang, L.; Luo, J.; Nie, Y.; Xing, Q.; Luo, X.; Du, H.; Luo, S.; Suib, S. Synthesis and efficient visible light photocatalytic $\mathrm{H}_{2}$ evolution of a metal-free $\mathrm{g}-\mathrm{C}_{3} \mathrm{~N}_{4} /$ graphene quantum dots hybrid photocatalyst. Appl. Catal., B 2016, 193, 103-109.

(29) Liu, Y.; Yu, S.; Zhao, Z.; Dong, F.; Dong, X.; Zhou, Y. N-doped $\mathrm{Bi}_{2} \mathrm{O}_{2} \mathrm{CO}_{3}$ /graphene quantum dot composite photocatalyst: enhanced visible-light photocatalytic NO oxidation and in situ DRIFTS studies. J. Phys. Chem. C 2017, 121, 12168-12177.

(30) Lim, S.; Shen, W.; Gao, Z. Carbon quantum dots and their applications. Chem. Soc. Rev. 2015, 44, 362-381.

(31) Pan, D.; Xi, C.; Li, Z.; Wang, L.; Chen, Z.; Lu, B.; Wu, M. Electrophoretic fabrication of highly robust, efficient, and benign heterojunction photo-electrocatalysts based on graphene-quantumdot sensitized $\mathrm{TiO}_{2}$ nanotube arrays. J. Mater. Chem. A 2013, 1, $3551-3555$.

(32) Zhou, L.; Geng, J.; Liu, B. Graphene Quantum Dots from Polycyclic Aromatic Hydrocarbon for Bioimaging and Sensing of $\mathrm{Fe}^{3+}$ and Hydrogen Peroxide. Part. Part. Syst. Char. 2013, 30, 1086-1092.

(33) Wang, L.; Wang, Y.; Xu, T.; Liao, H.; Yao, C.; Liu, Y.; Li, Z.; Chen, Z.; Pan, D.; Sun, L.; Wu, M. Gram-scale synthesis of singlecrystalline graphene quantum dots with superior optical properties. Nat. Commun. 2014, 5, 5357-5366.

(34) Liu, Y.; Yu, S.; Zheng, K.; Chen, W.; Dong, X.; Dong, F.; Zhou, Y. NO photo-oxidation and in-situ DRIFTS studies on N-doped $\mathrm{Bi}_{2} \mathrm{O}_{2} \mathrm{CO}_{3} / \mathrm{CdSe}$ quantum dot composite. Wuji Cailiao Xuebao 2019, 34, 425-432.

(35) Žídek, K.; Zheng, K.; Ponseca, C.; Messing, M.; Wallenberg, L.; Chábera, P.; Abdellah, M.; Sundström, V.; Pullerits, T. Electron transfer in quantum-dot-sensitized $\mathrm{ZnO}$ nanowires: ultrafast timeresolved absorption and terahertz study. J. Am. Chem. Soc. 2012, 134, 12110-12117.

(36) An, R.; Zhang, F.; Zou, X.; Tang, Y.; Liang, M.; Oshchapovskyy, I.; Liu, Y.; Honarfar, A.; Zhong, Y.; Li, C.; Geng, H.; Chen, J.; Canton, S.; Pullerits, T.; Zheng, K. Photostability and photodegradation processes in colloidal $\mathrm{CsPbI}_{3}$ perovskite quantum dots. ACS Appl. Mater. Interfaces 2018, 10, 39222-39227.

(37) Li, L.; Yan, X. Colloidal Graphene Quantum Dots. J. Phys. Chem. Lett. 2010, 1, 2572-2576.

(38) Yu, S.; Zhong, Y.; Yu, B.; Cai, S.; Wu, L.; Zhou, Y. Graphene quantum dots to enhance the photocatalytic hydrogen evolution efficiency of anatase $\mathrm{TiO}_{2}$ with exposed $\{001\}$ facet. Phys. Chem. Chem. Phys. 2016, 18, 20338-20344.

(39) Yin, S.; Liu, B.; Zhang, P.; Morikawa, T.; Yamanaka, K.; Sato, T. Photocatalytic oxidation of $\mathrm{NO}_{\mathrm{x}}$ under visible LED light irradiation over nitrogen-doped titaniaparticles with iron or platinum loading. J. Phys. Chem. C 2008, 112, 12425-12431. 
(40) Dong, F.; Lee, S.; Wu, Z.; Huang, Y.; Fu, M.; Ho, W.; Zou, S.; Wang, B. Rose-like monodisperse bismuth sub-carbonate hierarchical hollow microspheres: One-pot template-free fabrication and excellent visible light photocatalytic activity and photochemical stability for $\mathrm{NO}$ removal in indoor air. J. Hazard. Mater. 2011, 195, 346-354.

(41) Samal, M.; Mohapatra, P.; Subbiah, R.; Lee, C.; Anass, B.; Kim, J.; Kim, T.; Yi, D. InP/ZnS-graphene oxide and reduced graphene oxide nanocomposites as fascinating materials for potential optoelectronic applications. Nanoscale 2003, 5, 9793-9805.

(42) Bhattacharya, P.; Mi, Z. Quantum-dot optoelectronic devices. Proc. IEEE 2007, 95, 1723-1740.

(43) Kim, J.; Bae, S.; Yi, Y.; Park, M.; Kim, S.; Myoung, N.; Lee, C.; Hong, B.; Park, J. Origin of white electroluminescence in graphene quantum dots embedded host/guest polymer light emitting diodes. Sci. Rep. 2015, 5, 11032-11043.

(44) Liu, F.; Jang, M.; Ha, H.; Kim, J.; Cho, Y.; Seo, T. Facile synthetic method for pristine graphene quantum dots and graphene oxide quantum dots: origin of blue and green luminescence. Adv. Mater. 2013, 25, 3657-3662.

(45) Zhang, Z.; Zhang, J.; Chen, N.; Qu, L. Graphene quantum dots: an emerging material for energy-related applications and beyond. Energy Environ. Sci. 2012, 5, 8869-8890.

(46) Kim, J.; Park, M.; Kim, S.; Wang, D.; Cho, S.; Bae, S.; Park, J.; Hong, B. Balancing light absorptivity and carrier conductivity of graphene quantum dots for high-efficiency bulk heterojunction solar cells. ACS Nano 2013, 7, 7207-7212.

(47) Chen, Z.; Li, X.; Li, X.; Ye, G.; Zhou, Z.; Lu, L.; Sun, T.; Fan, $\mathrm{R}$; Chen, D. A correction method for range walk error in timecorrelated single-photon counting using photomultiplier tube. Opt. Commun. 2019, 434, 7-11.

(48) Yuan, F.; Yuan, T.; Sui, L.; Wang, Z.; Xi, Z.; Li, Y.; Li, X.; Fan, L.; Tan, Z.; Chen, A.; Jin, M.; Yang, S. Engineering triangular carbon quantum dots with unprecedented narrow bandwidth emission for multi-coloured LEDs. Nat. Commun. 2018, 9, 2249-2260.

(49) Li, H.; Shang, J.; Ai, Z.; Zhang, L. Efficient visible light nitrogen fixation with $\mathrm{BiOBr}$ nanosheets of oxygen vacancies on the exposed \{001\} facets. J. Am. Chem. Soc. 2015, 137, 6393-6399.

(50) Yang, B.; Chen, J.; Yang, S.; Hong, F.; Sun, L.; Han, P.; Pullerits, T.; Deng, W.; Han, K. Lead-free silver-bismuth halide double perovskite nanocrystals. Angew. Chem. 2018, 130, 5457-5461. (51) Jiang, L.; Wang, K.; Wu, X.; Zhang, G.; Yin, S. Amorphous Bimetallic Cobalt Nickel Sulfide Cocatalysts forSignificantly Boosting Photocatalytic Hydrogen EvolutionPerformance of Graphitic Carbon Nitride: Efficient Interfacial ChargeTransfer. ACS Appl. Mater. Interfaces 2019, 11, 26989-26908.

(52) Wu, X.; Li, Y.; Zhang, G.; Chen, H.; Li, J.; Wang, K.; Pan, Y.; Sun, Y.; Xie, Y. Photocatalytic $\mathrm{CO}_{2}$ Conversion of $\mathrm{M}_{0.33} \mathrm{WO}_{3}$ Directly from the Airwith High Selectivity: Insight into Full Spectrum-Induced ReactionMechanism. J. Am. Chem. Soc. 2019, 141, 5267-5274.

(53) Liang, N.; Wang, M.; Jin, L.; Huang, S.; Chen, W.; Xu, M.; He, Q.; Zai, J.; Fang, N.; Qian, X. Highly Efficient $\mathrm{Ag}_{2} \mathrm{O} / \mathrm{Bi}_{2} \mathrm{O}_{2} \mathrm{CO}_{3} \mathrm{p}-\mathrm{n}$ Heterojunction Photocatalystswith Improved Visible-Light Responsive Activity. ACS Appl. Mater. Interfaces 2014, 6, 11698-11705.

(54) Zai, T.; Cao, F.; Liang, N.; Yu, K.; Tian, Y.; Sun, H.; Qian, X. Rose-like I-doped $\mathrm{Bi}_{2} \mathrm{O}_{2} \mathrm{CO}_{3}$ microspheres with enhanced visible lightresponse: DFT calculation, synthesis and photocatalytic performance. J. Hazard. Mater. 2017, 321, 464-472.

(55) Chua, C.; Sofer, Z.; Simek, P.; Jankovský, O.; Klímová, K.; Bakardjieva, S.; Kučková, S.; Pumera, M. Synthesis of strongly fluorescent graphene quantum dots by cage-opening buckminsterfullerene. ACS Nano 2015, 9, 2548-2555.

(56) Maiti, S.; Kundu, S.; Roy, C.; Das, T.; Saha, A. Synthesis of excitation independent highly luminescent graphene quantum dots through perchloric acid oxidation. Langmuir 2017, 33, 14634-14642. (57) Zhu, S.; Zhang, J.; Tang, S.; Qiao, C.; Wang, L.; Wang, H.; Liu, X.; Li, B.; Li, Y.; Yu, W.; Wang, X.; Sun, H.; Yang, B. Surface chemistry routes to modulate the photoluminescence of graphene quantum dots: from fluorescence mechanism to up-conversion bioimaging applications. Adv. Funct. Mater. 2012, 22, 4732-4740.
(58) Lu, Y.; Huang, Y.; Zhang, Y.; Cao, J.; Li, H.; Shun, C.; Lee, C. Oxygen vacancy engineering of $\mathrm{Bi}_{2} \mathrm{O}_{3} / \mathrm{Bi}_{2} \mathrm{O}_{2} \mathrm{CO}_{3}$ heterojunctions: implications of the interfacial charge transfer, $\mathrm{NO}$ adsorption and removal. Appl. Catal., B 2018, 231, 357-367.

(59) Yang, C.; Xue, Z.; Qin, J.; Sawangphruk, M.; Rajendran, S.; Zhang, X.; Liu, R. Visible light-driven photocatalytic $\mathrm{H}_{2}$ generation and mechanism insights into $\mathrm{Bi}_{2} \mathrm{O}_{2} \mathrm{CO}_{3} / \mathrm{g}-\mathrm{C}_{3} \mathrm{~N}_{4}$ Z-scheme photocatalyst. J. Phys. Chem. C 2019, 123, 4795-4804.

(60) He, K.; Tsega, T.; Liu, X.; Zai, J.; Li, X.; Liu, X.; Li, W.; Ali, N.; Qian, X. Utilizing the Space-Charge Region of the FeNi-LDH/CoP p$\mathrm{n}$ Junction to Promote Performance in Oxygen Evolution Electrocatalysis. Angew. Chem., Int. Ed. 2019, 58, 11903-11909.

(61) Ma, D.; Hu, B.; Wu, W.; Liu, X.; Zai, J.; Shu, C.; Tsega, T.; Chen, L.; Qian, X. Highly active nanostructured $\mathrm{CoS}_{2} / \mathrm{CoSheter-}$ ojunction electrocatalysts for aqueouspolysulfide/iodide redox flow batteries. Nat. Commun. 2019, 10, 3367-3375.

(62) Lu, Y.; Huang, Y.; Zhang, Y.; Huang, T.; Li, H.; Cao, J.; Ho, W. Effects of $\mathrm{H}_{2} \mathrm{O}_{2}$ generation over visible light-responsive $\mathrm{Bi}$ / $\mathrm{Bi}_{2} \mathrm{O}_{2-\mathrm{x}} \mathrm{CO}_{3}$ nanosheets on their photocatalytic $\mathrm{NO}_{\mathrm{x}}$ removal performance. Chen, Chem. Eng. J. 2019, 363, 374-382.

(63) Yu, S.; Zhang, Y.; Dong, F.; Li, M.; Zhang, T.; Huang, H. Readily achieving concentration-tuneable oxygen vacancies in $\mathrm{Bi}_{2} \mathrm{O}_{2} \mathrm{CO}_{3}$ :Triple-functional role for efficient visible-light photocatalytic redoxperformance. Appl. Catal., B 2018, 226, 441-450.

(64) Yang, B.; Hong, F.; Chen, J.; Tang, Y.; Yang, L.; Sang, Y.; Xia, X.; Guo, J.; He, H.; Yang, S.; Deng, W.; Han, K. Colloidal synthesis and charge-carrier dynamics of $\mathrm{Cs}_{2} \mathrm{AgSb}_{1-\mathrm{y}} \mathrm{Bi}_{\mathrm{y}} \mathrm{X}_{6}(\mathrm{X}: \mathrm{Br}, \mathrm{Cl} ; 0 \leq y \leq 1)$ double perovskite nanocrystals. Angew. Chem., Int. Ed. 2019, 58, $2278-2283$.

(65) Ozer, L.; Apostoleris, H.; Ravaux, F.; Shylin, S.; Mamedov, F.; Lindblad, A.; Johansson, F.; Chiesa, M.; Sá, J.; Palmisano, G. Longlasting non-hydrogenated dark titanium dioxide: medium vacuum anneals for enhanced visible activity of modified multiphase photocatalysts. ChemCatChem 2018, 10, 2949-2954.

(66) Wei, T.; Zhu, Y.; Gu, Z.; An, X.; Liu, L.; Wu, Y.; Liu, H.; Tang, J.; $\mathrm{Qu}, \mathrm{J}$. Multi-electric field modulation for photocatalytic oxygen evolution: Enhanced charge separation by coupling oxygen vacancies with faceted heterostructures. Nano Energy 2018, 51, 764-773.

(67) Ding, J.; Dai, Z.; Qin, F.; Zhao, H.; Zhao, S.; Chen, R. Zscheme $\mathrm{BiO}_{1-\mathrm{x}} \mathrm{Br} / \mathrm{Bi}_{2} \mathrm{O}_{2} \mathrm{CO}_{3}$ photocatalyst with rich oxygen vacancy as electron mediator for highly efficient degradation of antibiotics. Appl. Catal., B 2017, 205, 281-291.

(68) Li, J.; Zhang, M.; Li, X.; Li, Q.; Yang, J. Effect of the calcination temperature on the visible light photocatalytic activity of direct contact Z-scheme $\mathrm{g}-\mathrm{C}_{3} \mathrm{~N}_{4}-\mathrm{TiO}_{2}$ heterojunction. Appl. Catal., B 2017, $212,106-114$. 